Revista Iberoamericana, Vol. LXXIII, Núm. 218, enero-marzo 2007, 129-143

\title{
AUGUSTO ROA BASTOS Y LOS CONJURADOS DEL QUILOMBO DEL GRAN CHACO (2001): UN LEGADO LITERARIO PARA LA INTEGRACIÓN LATINOAMERICANA
}

\author{
POR \\ Jorge Carlos Guerrero \\ University of Toronto
}

En un artículo publicado en La Nación a propósito del fallecimiento de Augusto Roa Bastos en abril del 2005, Tomás Eloy Martínez encomiaba el texto inédito que el autor le había enviado y que formaría parte de la obra colectiva Los conjurados del Quilombo del Gran Chaco (en adelante Los conjurados). El escritor argentino afirmaba que era una “obra maestra” sobre “el arte y la guerra”. Estimo que, además de esta dimensión universalista, el texto de Roa Bastos acerca de la Guerra de la Triple Alianza es una reflexión muy puntual en torno a dos temas fundamentales del debate cultural contemporáneo sobre América Latina: la regionalización y el latinoamericanismo. Los conjurados formula indirectamente la pregunta fundamental de la globalización: ¿̇e podrá superar la cartografía nacional que rige a los sujetos? Adicionalmente, pone el dedo en la llaga del latinoamericanismo al tematizar el primer gran nacionalismo de masas del continente y la guerra interamericana como una discontinuidad mayor de su genealogía.

Los conjurados relata la historia de una comunidad de desertores de la Guerra de la Triple Alianza (1865-1870) que se habría confabulado para ponerle fin al conflicto. La obra está conformada por cuatro textos cuyos autores (Roa Bastos, Alejandro Maciel, Omar Prego, Eric Nepomuceno) pertenecen a los países miembros del Mercado Común del Sur (Mercosur). El libro tuvo un amplio alcance regional en la medida en que se publicó también en Brasil con el título de O livro da Guerra Grande. El presente estudio tiene como enfoque principal la contribución de Roa Bastos a Los conjurados. Los segmentos "Frente al frente argentino” y "Frente al frente paraguayo" inician la escritura y abarcan casi la mitad del texto. Mediante una reescritura que hace dialogar textos contemporáneos a la guerra, Roa Bastos desvela tanto la íntima relación que estos guardan con la misma así como la compleja trama que rige la representación del conflicto. La escritura recupera la obra del gran pintor de la guerra, Cándido López, como expresión artística de un arte que se conjura, como los conjurados del Quilombo del Gran Chaco, contra la guerra y el nacionalismo. Esta ecfrasis de la obra del artista argentino le permite al autor reencuadrar dos textos que, a pesar de su aparente asepsia ideológica nacional, se revelan claves para desmontar las lecturas nacionalistas de la Guerra de la Triple Alianza: la traducción de El infierno de la divina comedia (1894) por Bartolomé Mitre y Cartas desde los campos de batalla en Paraguay (1870) de Sir Richard Burton. La reescritura de Roa Bastos, consciente de que el repliegue del estado no equivale al fin de la nación, plantea así los usos 
de la misma como la gran interrogante que acecha los proyectos de regionalización y cualquier postulación de una ciudadanía regional.

Roa Bastos dialoga fundamentalmente con el Mercado Común del Sur. Desde su conformación con el Tratado de Asunción de 1991, este proyecto de regionalización ha suscitado una impetuosa construcción discursiva que ya exhibe una amplia biblioteca multidisciplinaria. Una parte importante de la intelectualidad se ha abocado a imaginar la región. A grandes rasgos, el discurso de la integración recupera la tradición latinoamericanista y señala la precariedad epistemológica que sustenta la demarcación cultural nacional para reivindicar la pervivencia latente de una nación regional. El antropólogo argentino Alejandro Grimson se ha referido a la existencia de un "proyecto de ingeniería identitaria supranacional” para describir esta producción intelectual provocada por lo que yo describiría como de cierta ansiedad fundacional (17).

El prólogo de Los conjurados anuncia el proyecto textual, estableciendo un paralelo indirecto entre las condiciones actuales de la región y la antesala temporal de la Guerra de la Triple Alianza:

[En] la convulsionada Sud América, donde las dictaduras suceden a las montoneras, las anarquías a las asonadas. Ya no hay revoluciones. La misma superstición malgastada de repúblicas sembradas en un desierto de ideas regado con sangre, se convierte en rehén de grupos, corporaciones, estancieros y sátrapas de baja monta, que se disputan un poder siempre tambaleante, donde todos desconfían de todos, sin llegar a conformar un gobierno; o lo que es lo mismo, instituciones que sostengan el equilibrio del poder. (9)

Este contexto se transformó en el caldo de cultivo que dio lugar a la mayor guerra del continente y que culminó con el exterminio de una gran parte de la población paraguaya, lo que hace que el conflicto raye en el genocidio cultural (Chiavenato 8). Contra todas las predicciones iniciales, la guerra se transformó en una de las mayores del siglo XIX. La Guerra de la Triple Alianza plantea así antecedentes siniestros en las relaciones internacionales del Cono Sur. El conflicto se caracteriza por sus contradicciones. En primer lugar, fue una alianza regional para someter a Paraguay que, vinculado por un tratado de mutua defensa, se había aprestado a acudir al gobierno constitucional del Uruguay. El general uruguayo Venancio Flores, secundado logísticamente por Argentina, había invadido el país junto al ejército brasileño para derrocar al presidente Bernardo Berro. Esta primera alianza da lugar a la que se formaría contra Paraguay por haber participado precisamente en este conflicto platense.

Más allá del desencadenamiento puntual de la misma, la guerra se libró en nombre de la libertad de comercio, o sea: la versión decimonónica del discurso neoliberal contemporáneo, y en nombre de las libertades civiles y la democracia. El emblema de lucha contra la tiranía embanderaba paradójicamente a democracias formales de escasa representación. En segundo lugar, el revisionismo historiográfico de los sesenta señaló los intereses comerciales ingleses como otro elemento fundamental en el desencadenamiento del conflicto (Pomer 27). Por último, la guerra dispara el primer nacionalismo de masas en la región, lo que les permitió a los vencedores, principalmente a Argentina y a Brasil, establecer una cohesión nacional anteriormente inexistente así como, y merced a ello, abrir el camino a la modernidad institucional y económica (Whigman 179). 
El primer texto de Roa Bastos, "Frente al frente argentino”, exhibe una escritura polifónica que representa a dos figuras históricas vinculadas con la guerra: el pintor argentino Cándido López (1840-1902) y el general de las fuerzas argentinas y posteriormente presidente Bartolomé Mitre. El Cándido López histórico participó en el conflicto como oficial y pintor, aunque tras perder una mano en los primeros momentos de la guerra se dedicó exclusivamente a la representación artística del episodio bélico. Treinta años después de la guerra expuso una serie de veintidós cuadros titulada "Escenas de la Guerra del Paraguay”. Bartolomé Mitre es el letrado decimonónico en la acepción de Rama: estadista, general y hombre de letras. En plena Guerra de la Triple Alianza inició la traducción del Infierno de La divina comedia, texto que posteriormente publica en 1894 con el título de El infierno de La divina comedia.

En Los conjurados, mientras Cándido López hace bosquejos y pinta la guerra, Bartolomé Mitre traduce. El diálogo se caracteriza por los comentarios críticos sobre la representación pictórica de la guerra y sobre la traducción de La divina comedia. La representación, la traslación al lienzo o la traducción de un idioma al otro constituyen el mismo relato del texto. Las voces de Cándido López y Bartolomé Mitre se emplazan mutuamente y ambos dan razón de su trabajo:

\footnotetext{
¿Qué estás reflejando a fuerza de brochazos, pintor? El apresto de la batalla de Curupayti, donde murieron diez mil aliados y mi mano, general. ¿Vas a pintar la degollina y la decapitación manual? ¿Qué clase de maestro es el nuestro? Olvídese del pesado pasado, maestre de la paleta, aliviánelo. No hay mejor fe que creer en lo imposible. Mi pulso no miente, general, y más desde que le falta mi mano [....] Tu batalla perdida en el recuerdo también puede estar ganada en la imaginación. Hay que inventar la gloria, maestre. Si nuestras tropas recularon, hazlas avanzar en tu lienzo. Tutela tu tela mirando con un ojo el pasado y con el otro, el recuerdo. No reconocerás al uno en el espejo del otro. Ya ves, este paisaje de sangre parece un mal sueño. ¿̇ qué importa si está al revés o al través? Lo que importa es el recuerdo que tendrá el porvenir. La memoria del pueblo que mira desde adelante para atrás. Todo se puede mejorar siempre, maestre. El arte es el arma para corregir la realidad. (12)
}

La obra pictórica del Cándido López histórico se caracteriza por un tratamiento detallado de las imágenes en las cuales recrea minuciosamente los momentos del día, las condiciones climáticas, los pertrechos de la guerra y los atuendos. Los cuadros socavan la centralidad histórica que se adjudica el hombre al plasmar los acontecimientos en un devenir mayor acentuado por su lugar en una naturaleza imponente. Loizaga comenta que los románticos e incluso los neoclásicos representaban la guerra a través de la exaltación de las batallas y sus protagonistas. El paisaje era apenas un telón de fondo que contribuía a engrandecer la hazaña militar. La pintura de Cándido López trastoca los elementos otorgándole preponderancia a la naturaleza por sobre las operaciones militares (61).

Desde una perspectiva narratológica, Gache señala que el esquema narrativo que sustenta las pinturas del artista sobre la batalla de Curupaytí, centrales para la reconstitución de su obra en Los conjurados, se caracterizan por: 1) un registro de acciones múltiples en una misma pintura, 2) cada imagen desarrolla una historia embrionaria, 3) una presentación de la batalla desde diferentes puntos de vista, 4) una focalización siempre externa, 5) un 
espacio dividido en dos campos diferenciados de sujetos y anti-sujetos) (2-5). En su propuesta de visión objetiva total, Cándido López adopta múltiples puntos de vista, incluso el del campo enemigo. La única posible excepción al objetivismo de su modelo de representación sería su autorrepresentación: en los cuadros de la batalla también aparece dos veces un autorretrato en el momento que una granada le amputa la mano, representada como la izquierda en uno y como la derecha en otro. Este desdoblamiento, que lo hace tanto objeto como sujeto de la narración, tematiza la misma representación y se reconstituye espectralmente en el libro. En Los Conjurados, Bartolomé Mitre le advierte al pintor aludiendo a Las Meninas: “Cuidado con acercarte demasiado a Diego Velásquez” (28). Por otra parte, el autor implícito lo textualiza estructuralmente: los segmentos "Frente al frente argentino" y “Frente al frente paraguayo” proponen también un desdoblamiento de la mirada que se torna objeto y sujeto de representación. Desde una mirada interior, ambos tratan respectivamente lo que sucede en el frente argentino y paraguayo de la guerra. Hay, por lo tanto, un juego implícito en Los conjurados que narra justamente lo contrario de la exterioridad de la mirada sugerida en los títulos.

En lo que se puede llamar una écfrasis, el arte de Cándido López en Los conjurados muestra una fisura o vacilación nacional para su época justamente por anteponer su afán documentalista a la vocación nacionalista. El documentalismo de Cándido López esquiva una representación épica del papel argentino en la guerra. El personaje de Bartolomé Mitre critica la hesitación de Cándido López y exige una función cívica de la representación, una pintura que contribuya al imaginario nacional argentino. Al mismo tiempo, impugna la exterioridad de la mirada que se desdobla y por lo tanto separa al pintor del frente argentino cuando le dice: "En plena refriega te veo mirando desde la altura cómo los hombres se trenzan en combate [...]” (23). Igualmente desaprueba el realismo de la imagen a través del rechazo de su inmediatez, sin perspectiva histórica, o sea sin dimensión ideológica o visión teleológica de la razón de estado. “La memoria del momento es la más engañadora. Nunca estamos en el tiempo presente, salvo en la memoria que acopia, como la tuya copia. Toda historia contemporánea es un fraude” (23). La pintura de Cándido López en Los conjurados, al no seguir las pautas épicas de la historia nacional, que el mismo Mitre escribe, denuncia el discurso del poder. Bartolomé Mitre es el gran historiador nacional argentino o, en la formulación del historiador Halperín Donghi, “el autor de la metanarrativa nacional” (52). Los conjurados textualiza esta perspectiva en el personaje de Bartolomé Mitre. De ahí que éste anteponga exasperadamente la escritura a la pintura: "Garabatea, maestre, graba a buril, enyesa frescos de las batallas calientes. Tus imágenes nunca serán más fuertes que los escritos" (29).

En Picture Theory, W.J.T. Mitchell argumenta que la écfrasis es la representación verbal de una representación visual (152). Según el crítico, lo verbal tendría la capacidad de subsumir lo visual; lo verbal sería lo activo contrastado con la pasividad del silencio de la imagen. El texto visual y el texto verbal se entrecruzarían figuradamente puesto que aquél solamente se haría presente mediante la convocación de la palabra. Mitchell también ha descrito tres momentos de enfrentamiento entre lo verbal y la fuente de inspiración visual. Se refiere a un momento de "esperanza ecfrástica” en que la imposibilidad de la écfrasis se supera; ese momento, el tercero en la tríada de Mitchell, es cuando el lenguaje nos hace ver mediante la imaginación y la metáfora (152). Siguiendo este razonamiento, 
la escritura de Los conjurados es la presencia que conjura la pintura de Cándido López. El autor implícito hace presente la pintura de Cándido López al entramar al individuo histórico tanto como personaje en el momento de creación así como partícipe en el debate sobre su modo de representación pictórico. La reconstitución textual que sustenta el tropo de la écfrasis es así metaliteraria puesto que pone en el centro de la recuperación de la imagen la cuestión de las operaciones retóricas de la representación. El momento de la "esperanza ecfrástica” de Los conjurados radicaría en sobreponerse, mediante la confrontación textual, al triunfo agorado por la metanarrativa nacional de Mitre.

El Mitre histórico es la gran figura del discurso nacional argentino mientras que el artista Cándido López quedó en el olvido durante más de un siglo. A inicios del siglo XxI, cuando el estado nación entra en crisis y sus discursos fundacionales se rescriben para desdibujar las fronteras que compartimentan las nacionalidades, la literatura recupera la pintura de Cándido López. El documentalismo pictórico se aviene a los proyectos culturales en curso en tanto que la exaltación épica se torna parte del museo del oprobio. El liberalismo nacionalista de inicios del siglo xx hizo una lectura patriótica de su obra. Cándido López, mediante una mimetización de su biografía, fue el patriota que conmovido por los sentimientos nacionales reeducó el brazo izquierdo para dedicarse con devoción a la representación de la guerra. En Los conjurados, del marco forjado por la ficción surge una lectura que deslegitima la apropiación nacionalista y rescata otro Cándido López.

Por un lado, la escritura desapropia entonces al archivo nacional de la obra de Cándido López y por otro, como demostraré a continuación, reencuadra nacionalmente la traducción de La divina comedia. El libro denuncia la aparente asepsia de la práctica escrituraria del traductor Mitre. El diálogo de los personajes de Cándido López y Bartolomé Mitre reconstruye las nociones sobre la traducción expuestas en "Teoría del Traductor”, prólogo escrito por Mitre con fecha de 1889 a su traducción de La divina comedia. Aquí, el traductor Mitre afirma que "las obras maestras deben traducirse al pie de la letra para que sean al menos un reflejo (directo) del original, y no una bella infidel” (6). El componente fundamental de toda traducción, el ideal, es el "penetrarse del espíritu de la obra, como el artista que, al modelar en arcilla una estatua, procura darle no sólo su forma externa, sino también la expresión reveladora de la vida interna” (7). En lo que respecta a su Divina comedia dice que es “una traducción fiel y una interpretación racional, matemática a la vez que poética”. Mitre también explica las circunstancias de la traducción. Se trata de un proyecto postergado de más de cuarenta años. Si bien siempre se sintió "impregnado de su espíritu”, consideraba el proyecto "intraductible en toda su intención" (7). En Los conjurados se induce del prólogo de Mitre que el traductor captó toda la “intención del texto” durante la Guerra del Paraguay y que en ese momento “emprendió la tarea por vía de solaz” y la continuó después como “propósito serio” (8).

El personaje de Cándido López condena la dimensión mecánica, la literalidad, la traslación matemática de forma y contenido, el uso de un castellano arcaizante del Siglo de Oro, así como debate sobre el ideal de la traducción según Mitre. Ambos discurren al respecto:

Pedro Mártir dijo que el Alighieri no pudo escribir su Commedia en el latín de la época, no le alcanzaba el vulgar y el erudito sobraba. Entonces inventó un idioma nuevo para 
mentar a las almas después de la muerte. De mentar a mentir hay un paso, don. ¿Por qué no miente al menos? Invente otro idioma para mentar su equivocación, que está exterminando a estos cristianos? ... Yo también sufrí hasta que pude encontrar los colores apropiados para pintar el crimen, créame (32).

La refutación constante de Cándido López consiste en infundirle a la traducción las circunstancias de la guerra, que según él, traducirían contemporáneamente el espíritu de la obra. Esta noción de traducción cultural se relaciona con la propuesta de Walter Benjamin. Para éste la tarea del traductor vendría a ser la reconstrucción del diálogo, de una concordia cultural, a través justamente del señalamiento de la precariedad de toda lengua. Una traducción fidedigna sería aquella capaz de revelar la añoranza de una fusión lingüística y el buen traductor, aquel llamado a liberar la lengua cautiva en el original mediante su recreación (82). Por su lado, Derrida lo formula en los siguientes términos:

La traduction sera en vérité un moment de sa propre croissance [de l'original], il s'y complètera en s'agrandissant. [...] ainsi, de même que les débris deviennent reconnaisables comme fragments d'une même amphore, original et traduction deviennent reconaissalbes comme fragments d'un langage plus grand. (210)

En la concepción de Benjamin la traducción es una escritura híbrida que camina entre el original y la lectura crítica. Derrida señala que una traducción relevante es también una traducción recíproca (213) o “a double bind”, en la formulación de Spivak (XXXVII). El traductor, en resumidas cuentas, se encuentra en un espacio intermedio, en el límite de la lengua donde el pensar se sitúa. Habitar el "entre” las lenguas implica una reflexión sobre la identidad y la nación puesto que traducir atañe a la presencia del otro: la otra lengua y la otra cultura ("Des tours de Babel” 250).

En Los conjurados, Cándido López contradice el concepto de fidelidad en la traducción de Mitre al confrontarlo con sus máximas implicaciones, es decir, su diálogo con el otro. El personaje desvía la temática general de cada círculo (limbo, lujuria, ira, etc) hacia las razones de la guerra, y de ahí cuestiona tanto los fundamentos ideológicos del conflicto así como la misma traducción de Mitre. "Hay un infierno escrito en los versos y otro que leemos en esta tierra de bárbaros”, replica Mitre (21). Si toda traducción es extrañamiento, diálogo con el otro, la guerra, que es exactamente lo contrario, es decir, solipsismo identitario, contradice la labor del traductor. Cándido López impugna la distinción de Mitre en el diálogo:

El Dante fundó el infierno, maestre. Únicamente la poesía podía edificar desde la nada pero esa misma virtud fue su mayor defecto; la palabra escrita es falsa. Quiere ser el nombre del infierno, el mismo infierno, la condenación y su salvación, todo a la vez. Vamos a conocer el Infierno leyendo al Dante, maestre. ¿Dónde cree que estamos, general? Deberías pintarlo. ¿Qué cree que estoy haciendo? ¿No ve aquí la artillería aliada, más allá la infantería paraguaya? ¿Y dónde fue ese combate, ayudante? (25)

La voz del artista, la écfrasis de la pintura de Cándido López, reclama para sí una representación del Infierno que igualmente interpela a la de la traducción de Mitre. Habría 
un infierno sudamericano que debería entrar en esta traducción. Cándido López denuncia así la incapacidad de Mitre para “traducir” la lengua americana. Mitre niega a América en su traducción filológica con el uso del español del Siglo de Oro así como desconoce el infierno de la guerra devastadora contra "esta tierra de bárbaros” (31). Me refiero aquí al lema de civilización o barbarie de su correligionario Sarmiento cuyo orientalismo textual niega lo americano. Mitre postula su traducción dentro de una textualidad europea que borra la cultura americana implícita como exigencia de reciprocidad en la traducción.

En este sentido, Cándido López corrige a continuación unos versos del quinto círculo:

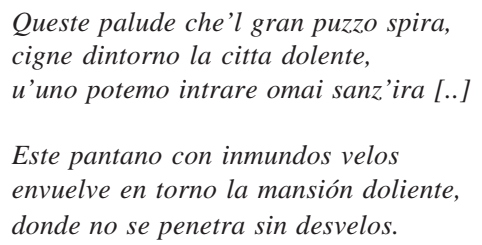

¿Por qué usa palabras abastardadas, general? ¿Por qué no decir donde nadie entra sin desvelos en vez del artificioso penetra? Usted pone un muro entre el Dante y mi propio infierno. ¿Por qué mansión donde dice ciudad? Derrueque la bizarría de tanto barroquismo inútil, sir. Vaya a lo simple. (42)

El “barroquismo” de Mitre no sólo plantea un problema lingüístico sino que apunta a un referente ajeno al infierno de la representación pictórica de Cándido López.

El texto sugiere el momento en que el pintor hace una brecha en el discurso del poder. Mitre, acosado por la argumentación, se explica a través de una escisión identitaria: "Ya está visto que nunca vas a comprender el estado del Estado. Yo no soy yo. Cuando decido acciones de gobierno Bartolomé Mitre está a un lado ...” (44). Este desdoblamiento explicaría su traducción como "solaz". En su lectura de La divina comedia, Dante "hizo un infierno donde la justicia corrige lo que la política mal rige en el mundo. Es un sueño en el mañana para enderezar las pesadillas de ayer" (49). Cándido López retruca: "Para qué vivir si no podemos rectificar algún retazo de justicia en un mundo manifiestamente inicuo y arbitrario” (48). Las impugnaciones del poder al artista son devueltas y éstas al mismo tiempo desarticulan el discurso del poder que acaba escindiéndose para justificarse.

El diálogo desemboca en un punto muerto, en un monólogo de Mitre, que a su vez abre las posibilidades de una recepción crítica comprometida. Haciendo caso omiso de la argumentación del pintor, Mitre continúa ensimismado con su traducción. El texto culmina con las últimas estrofas del canto XXVIII del Infierno, pero las impugnaciones del artista le confieren ahora al texto obvias resonancias. En este canto de La divina comedia ('Aro noveno: diseminadores de la discordia'), la voz poética discurre retóricamente sobre las limitaciones de la lengua para describir el Infierno. Antes de pasar a la descripción del noveno abismo, Dante nos prepara con la descripción de una serie de guerras: Troya, Cartago y los conflictos del siglo XIII. La voz poética describe cuerpos descuartizados, literalmente escindidos, hasta llegar a la focalización en el hombre que le 
dice: "Ve cómo la entrañas me resaco". En este canto la mirada exigida por el hombre a la voz poética, y la escritura de La divina comedia que el lector confronta, coinciden en una doble perseverancia: la de la violencia patente en el orgullo que muestra el hombre en su auto flagelo y la de la capacidad de la voz poética para describir lo anunciado, al inicio del canto, como inefable.

El texto de Roa Bastos presenta solamente la traducción de cinco estrofas de entre las últimas diez de este canto. En esta parte del canto, la continuación de lo descrito anteriormente, hay una pausa, momento de reflexión poética antes de pasar a la descripción final, que se da primero en la visión de la voz poética y luego en forma de apóstrofe:

Quedé a mirar la condenada turba, y cosa vi que me causó pavura, y que el solo contarla me conturba;

mas la firme conciencia me asegura, como fiel compañera que da aliento bajo el albergue de una mente pura.

Yo vi cierto, y lo veo en el momento, un busto sin cabeza ir caminando en medio de aquel triste agrupamiento.

La cabeza del pelo iba colgando en sus manos, a modo de linterna, y "Ay de mí", clamaba sollozando.

[aquí existen cinco estrofas no transcritas en Los conjurados]

Por dividir lo que se hallaba unido tengo así dividida la cabeza, principio de este cuerpo amortecido;

y culpa y pena así se contrapesan (53)

La última estrofa, y más explícitamente las cinco faltantes, apuntan a una identidad entre el traductor Mitre y el objeto de la mirada. En el poema, el hombre que lleva la cabeza en la mano es Bosnio Beltrán, el poeta provenzal que siembra la discordia y causa la guerra. En la traducción que se despliega ante el lector, la traducción de Los conjurados, tras un largo diálogo de impugnaciones que concluye en estas estrofas, la voz del traductor y la voz del condenado se sugieren como una misma identidad. En esta identificación, o acusación solapada contra Mitre, el texto recrearía el criterio de fidelidad postulado por Cándido López puesto que, mediante una mise-en-abîme, tematiza la escisión identitaria de Mitre. El "Yo no soy yo" de Mitre se reproduce en la imagen del hombre que se regocija en el dolor como el traductor Mitre, quien se escinde como "solaz” en la traducción del Infierno de Dante en el infierno de la guerra.

Leo esta conclusión como una exigencia para con el lector que debe leer las últimas estrofas y suplementarlas con la lectura crítica de los textos. De esta recepción activa 
resulta una identificación de Mitre con el poeta provenzal que le confiere al lector el estatus de conjurado también. Al igual que los conjurados del Quilombo del Gran Chaco, cuyo plan consistía en eliminar a los líderes de la guerra, el lector deconstruye la figura de Mitre al traducir La divina comedia en el contexto sudamericano que el texto de Roa Bastos hace patente.

Si toda traducción fiel o relevante es una traducción recíproca, en lo que se podría considerar La nueva divina comedia de Los conjurados, los infiernos se confunden. Es decir: Mitre, reencuadrado en Los conjurados y en una reconstitución de la reciprocidad del acto de traducir, vuelve a traducir La divina comedia. Los conjurados, en este momento clave de la lectura, manifiesta su fidelidad al original al reproducir la guerra que es la ocasión de su traducción. Propongo leer a Cándido Lopez como el guía de Mitre en esta nueva traducción del Infierno de Dante. Spivak considera que la traducción es la lectura más dolorosa porque implica una reescritura, o sea: un procedimiento esencialmente intertextual (XXXVI). La divina comedia de Mitre es el gran intertexto de la escritura de Roa Bastos y se construye precisamente tomando como base el señalamiento de su limitación como traducción tanto lingüística como cultural. El Mitre de Los conjurados, ensimismado con los problemas de filología histórica y precisión matemática, no rescribe La divina comedia en la lengua de la cultura sudamericana. Su lengua borra las circunstancias de la traducción como si de alguna manera pudiera convivir en un universo de formas ideales donde el traductor se aboca a identificar correspondencias. Cándido López denuncia precisamente el infierno que habría visto Dante pero que la poesía de Mitre no ve (53).

La traducción de La divina comedia de Mitre en Los conjurados remedia las limitaciones de la primera. Esta traducción es una nueva traducción puesto que surge de un diálogo recíproco con la alteridad que incorpora a la cultura del mismo traductor. Se realiza ahora en un intercambio con la circunstancia, la cultura y la lengua que la engendró: es decir, el nacionalismo acendrado de países en plena consolidación. En Los conjurados Mitre es la voz letrada erudita, el modelo cultural del siglo xIx, el hombre de armas y de letras, pero también es Bosnio Beltrán, el poeta y político que siembra la discordia y en el infierno se deleita escindiendo su cuerpo como Mitre, al pretender librar una guerra genocida y ser traductor fiel del "Infierno" de Dante. La traducción de Mitre tiene ahora otra versión, otro texto, el de Los conjurados, que viene a actualizarla, a traducirla en la cultura regional sudamericana.

En resumen: la escritura reencuadra la obra de Mitre y de Cándido López, y este contexto propiciado por la ficción opera como un disparador de estos textos culturales que emergen del pasado bajo otra luz. La primera traducción del Infierno de La divina comedia, al ser extraída de la neutralidad de la traducción como correspondencia lingüística, revela una fisura o esquizofrenia en el transcurso del letrado nacional. Este intersticio en la trayectoria del hombre ilustre surge nada más y nada menos que de la obra pictórica rescatada de entre los discursos nacionalistas del abolengo mitrista.

La segunda contribución de Roa Bastos a Los conjurados, "Frente al frente paraguayo”, cierra simétricamente el círculo de la guerra. A diferencia del primer segmento, un intelectual lee críticamente Cartas desde los campos de batalla en Paraguay (1870) de Richard Burton (en adelante Cartas). El texto está dividido en tres partes. La primera es 
la lectura crítica y reescritura de las Cartas y se titula "Recuperando lo escrito”; la segunda es "El guerrero y su doble”, y el título de la tercera es “Oficios bárbaros”. La primera sección comprende la mayor parte del texto y las dos restantes se remiten a las últimas páginas. En la primera, el narrador adopta un estilo ensayístico interpretativo que se abandona a veces por una recreación de escenas dialogadas en la comandancia del frente paraguayo. Las últimas dos partes son ensayos sobre el tema del arte y la violencia.

El texto empieza con una discusión sobre la historiografía de la guerra:

A lo largo de más de un siglo, la historia de la Guerra Grande (llamada de la Triple Alianza) continúa siendo materia de controversias y discusiones, de querellas y duelos interminables. A pesar de haberse escrito sobre ella bibliotecas enteras, sigue siendo totalmente desconocida. La historia oficial de los vencedores no ha hecho sino oscurecerla aún más y tornarla inverosímil como una tragedia que no ocurrió ni pudo haber ocurrido. (55)

La ocultación resultante de la profusión historiográfica nacionalista viene a autorizar la ficción de Los conjurados. En la propuesta de Roa Bastos, el pasado surge del recorrido de textos (pinturas, traducciones, cartas) que iluminan un espacio inusitado de la historia regional. Si las historiografías nacionales tornan inverosímil el pasado, le cabría a la literatura su recuperación. Sin embargo, el texto parodia también la inverosimilitud de las historiografías poblando la reconstitución de su propio pasado de seres ficticios extraordinarios. Hacia el final del texto el narrador hace una evaluación de las Cartas que es en realidad un comentario metaliterario sobre su utilización en Los conjurados:

Hay que volver al libro del traductor de las Mil y una noches para saber algo más sobre algunos de los extraños personajes de la Guerra Grande. Los cronistas locales y extranjeros, por alguna razón de pudor histórico tal vez, han preferido no ocuparse de ellos. O lo han hecho con tal ambigüedad, que estos personajes semejan aparecidos de una historia fantástica. (91)

En la versión de las Cartas reproducida en Los conjurados, las figuras históricas pueden vivir circunstancias eminentemente ficticias o aparecer personajes cuya existencia es estrictamente literaria a pesar de las afirmaciones de lo contrario.

El narrador anuncia que Burton "relata episodios de la vida de los campamentos [del mariscal y presidente paraguayo] López y aporta elementos nunca tratados por los profesionales de la historia sobre el debatido y nunca aclarado final de la contienda” (56). La guerra finalizó en 1870 y Burton escribió su última carta en 1869. La reescritura presenta glosas de cartas en realidad inexistentes, pero que el narrador insistentemente reitera que es una transcripción comentada (74). El autor implícito suplementa Las cartas no sólo con un período no tratado por el propio Burton sino también con la transformación del narrador en personaje. “Frente al frente paraguayo” viene a reflejar así espectralmente "Frente al frente argentino” y a continuar la misma reflexión sobre la representación que atraviesa la totalidad del texto. El mismo narrador lo comenta cuando pone en boca de Richard Burton una reflexión sobre los cambios que le hace a los cuentos de Las mil y una noches y que, por la noche, le relata a Elisa Lynch: "Me detuve un instante embargado por 
la originalidad del imprevisto hallazgo narrativo (la narradora convertida en personaje de un cuento desconocido para ella, de una historia que no está en el Libro)” (73). Richard Burton, como Cándido López o Bartolomé Mitre, es en Los conjurados personaje de un cuento que desconoce.

La recreación de una supuesta estadía en la comandancia paraguaya le permite al autor implícito representar un diálogo entre Solano López y Richard Burton sobre la guerra, paralelo al que mantiene Cándido López con Bartolomé Mitre. Esta incorporación de Burton, como personaje y autor de Las Cartas en Los conjurados, apunta a una reflexión sobre el objeto de su escritura, es decir, la representación que hace Burton de la guerra. El texto parodia ese orientalismo que, como propone Said, es una práctica discursiva que le permite a Occidente producir al Oriente tomando como base un sistema de conocimientos que enfatiza la diferencia. De este ejercicio de comparación diferencial se construye un Oriente atrasado, primitivo e inferior que legitima la misión civilizadora occidental (15). La existencia de Las Cartas y el lugar fundamental que han ocupado en la génesis de la historiografía de la guerra, revelan el entramado geopolítico que ubica a un escriba del imperio inglés como detentador y productor de conocimiento sobre un momento clave de las relaciones internacionales en América del Sur.

Toda reescritura equivale a un suplemento de la lectura crítica del nuevo narrador que suplanta la identidad escrituraria del texto original. Rescribir Las Cartas de Burton en Los conjurados significa desmontar los múltiples ejes que manifiesta su representación orientalista mediante la parodia de tornar objeto de escritura al propio sujeto; esta escisión permite entramar al sujeto en plena construcción de su discurso. Por un lado, el Richard Burton de Los conjurados es el adherente al proyecto nacional del gran orientalista latinoamericano, Sarmiento, ${ }^{1}$ a quien le dedica el libro. El narrador así lo transcribe: "Desde una óptica imparcial, la guerra del Paraguay es nada más y nada menos que el funesto destino de una raza que debe ser liberada de una tiranía elegida por ella misma” (54). Sin embargo, Burton experimenta también la misma fascinación con lo que rechaza al demostrar admiración por el mariscal paraguayo Solano López (54). Esta parodia del contradictorio movimiento de deseo y rechazo que caracteriza la construcción orientalista, tiene su mayor grado de ironía en los esfuerzos inútiles de Burton para seducir a la irlandesa Madame Lynch en términos del erotismo oriental. El texto hace una reconstrucción irónica del apetito sexual exótico que no es más que un deseo narcisista. En un paralelo revelador de su empresa imperial, “Dirty Dick Burton” le relata cuentos veladamente eróticos de las Mil y una noches. La primera dama está, por ende, igualmente entramada en un relato que desmonta la red discursiva que en toda narración nacional le atribuye encarnar “sinecdóticamente” el maternal cuerpo sin mácula de la nación. En definitiva, el desmontaje de Las Cartas mediante su reescritura revela, simétricamente, problemas

\footnotetext{
${ }^{1}$ El texto fundacional emblemático de América Latina -Facundo (1838)- exhibe justamente esa representación de lo americano en los términos de la representación establecida por el archivo orientalista europeo. Esta operación le asigna al territorio una distinción geográfica básica impregnada de orientalismo y funciona con el plan de controlar e incorporar lo diferente. Ver Desencuentros de la modernidad en América Latina (1989) de Julio Ramos o "El orientalismo y la idea del despotismo en el Facundo" (1997) de Carlos Altamirano.
} 
epistemológicos análogos a los planteados en la traducción de Mitre y que señalan una incapacidad para confrontar la alteridad.

Este desmantelamiento de la representación orientalista de Burton tiene su contraparte en la deconstrucción de la figura del héroe nacional paraguayo. Solano López es un hombre pequeño y plagado de dolores de muelas que desfiguran terriblemente su cara. Es también el mariscal implacable que fusila o encarcela a sus más allegados colaboradores y familiares. Hay una presentación grotesca de Solano López que desmonta la figura idealizada del nacionalismo paraguayo y cuestiona la prepotencia que le permite identificarse con el destino de un país y, por lo tanto, sacrificarlo en la guerra. Por otro lado, la deconstrucción del orientalismo de Burton desmonta los discursos nacionales de aliados que no admiten una interpretación dependiente de su política bélica puesto que atentaría contra el mismo principio de soberanía nacional y sus construcciones discursivas. Las cartas de Richard Burton desempeñaron un papel fundamental en la genealogía de la historiografía de la guerra puesto que durantes varias décadas constituyeron una de las pocas fuentes sobre el conflicto (Brezzo 113). El texto del cónsul y espía inglés revela, por su conocimiento local, un entramado geopolítico que liga soberanías nacionales a intereses imperiales. La misma existencia documental e interpretativa de la visión panóptica del sujeto imperial señala la dependencia y precariedad nacionales. En conclusión, las historias nacionales quedan resumidas en el accionar de individuos que parecen incapaces de defender los intereses estatales a pesar de los nacionalismos exacerbados por sus discursos.

Hacia el final del texto, Las cartas de Burton le permiten al autor implícito reflexionar sobre la propuesta que anima la misma reescritura de Los conjurados. El narrador anuncia que habría una carta dedicada a un Cándido López paraguayo:

Burton vio y admiró esos cuadros que iban saliendo “del natural” pero también de una visión de ultratumba; incluso vio pintar a Cándido López, sentado entre los muertos, al final de una batalla. "Parecía un sordomudo o un sonámbulo fuera del mundo real", escribe en una de sus cartas (la decimotercera), totalmente dedicada al pintor. (58)

El pintor paraguayo, metáfora de la destrucción, pierde la mitad de su cuerpo y pinta con el pincel entre labios (59). El narrador fabula glosando la carta y así constituye identitariamente a este doble paraguayo en la propia escritura: “Toda realidad simbólica puede desplegarse en múltiples y diferentes configuraciones. Algunas de ellas son las leyendas que son capaces de generar” (97). En lo que es una elaboración de lo que acaba de afirmar, el narrador señala "performativamente", en el sentido que construye la leyenda al nombrarla, que "existe en mi país una versión legendaria de otro pintor llamado también Cándido López” (98). Posteriormente presenta una minibiografía del pintor:

El homónimo paraguayo del argentino era a su vez uno de los asistentes del Mariscal López .... Los nombres y las funciones de ambos tocayos eran semejantes. Dios no juega a los dados pero al azar sí.... Ambos Cándido López, el argentino y el paraguayo, han estado combatiéndose sin conocerse a lo largo de cinco años de guerra .... La leyenda sinuosa continúa la vida. Relata de un modo casi fantasmagórico la aparición de este segundo Cándido López, ya hacia el final de la guerra .... 
El Cándido López paraguayo... sí pintaba las escenas del bárbaro oficio ... Pintor del martirologio de su pueblo, transmigrante de su homónimo argentino y tal vez su doble astral y oscuro, se funde con él en el tiempo que lo envuelve en sus membranas invisibles. Desde la leyenda se abrazan, y por encima del horror celebran ambos la fraternidad de los pueblos en la glorificación de la vida siempre más fuerte que la muerte. (100)

La gemelaridad, la identidad antropológica común a todas las culturas, alude a una identificación intercultural más allá de las categorías históricas. Por sobre las categorías identitarias hay principios que hermanan a la humanidad y que validan el conjurarse contra el imaginario cartográfico que las sustenta.

Esta propuesta de Roa Bastos as afín a la reflexión teórica de Mihai Spariosu sobre la literatura. Spariosu, tomando como base la propuesta antropológica de Turner, ha propuesto lo liminal como vía para sortear conflictos y generar mundos alternativos (28). Esta propuesta se aleja de la dicotomía de margen y centro del espacio liminal de Bhabha (1994) y postula una cosmovisión antiantagónica para el discurso cultural. El crítico argumenta que en lo liminal las tensiones antagónicas se neutralizan y se sostienen en un inestable equilibrio. Esta propuesta procura superar la cosmovisión antagónica de la cultura mediante la recuperación de tradiciones conciliadoras dentro y fuera de la cultura occidental. En esta perspectiva le asigna a la literatura una función conciliadora resultante de su carácter lúdico y liminal. ${ }^{2}$

Independientemente de su posible aplicación a toda la literatura, esta perspectiva conciliatoria ('irenic perspective' del griego Eirene, diosa de la paz) es central al proyecto textual de Roa Bastos y constituye su legado literario para la integración. Roa Bastos centra su perspectiva conciliatoria en la fabulación de una gemelaridad intercultural que se rescata de la obra de Cándido López. La prosa ensayística que cierra el texto efectivamente explicita la lectura de la obra de Cándido López que sustenta la ecfrasis:

López no pretendió hacer alegorías del “bárbaro oficio” ... no cedió en ningún momento
a la exaltación épica del vencedor ni al desdeñoso desprecio del vencido. ¿Desde dónde
pintó tantas escenas de crueldad detenida? ¿Desde el teatro épico de una guerra sin
sentido? ¿Desde la memoria, que es la trastienda y la trampa de escena desde donde la obra
recobra un arte sin artificios? Cándido López pintó el presente de las escenas de guerra
con la visión del futuro y la recordación del pasado, para conjurarlo en la dimensión
metafísica del sufrimiento de los pueblos. Juega dramáticamente haciéndonos sentir lo
que se debe recordar, lo que se debe evocar en la memoria viviente contrapuesta a la

2 "Since literary discourse belongs to a playful, liminal mode of being, it is not bound by the logical and analytic methods of philosophical and scientific discourse and, therefore, can also propose alternative models based on irenic principles. Furthermore, literature as a form of aesthetic play can both involve and transcend the sociocultural context in which it arises. Unlike other types of discourse, it can adopt an as if stance toward the ethical norms of a certain community or culture. Consequently it can produce, in the imagination, new sets of values that can later be adopted by ethical and sociopolitical thought as well. By playfully staging a real or an imaginary world and presenting it from various perspectives, literature contributes to a better understanding of the ethical choices open to a certain community and hence can assume an important role in bringing about historical change” (Spariosu XVI). 
penumbra y a las deformaciones de la mala memoria, tocada por el hálito de la muerte que impregnaba los campamentos, los esteros, los campos de batalla arrasados. El aire límpido de sus visiones barre el hedor de la muerte y lo sustituye por el fuerte aroma de la vida, en la que late la potencia de los renacimientos y las resurrecciones. Sus cuadros no son una apología de la guerra. Son más bien su plácida y serena negación. (97)

La propuesta literaria de Roa Bastos postula un espacio liminal en el cual la representación pictórica de Cándido López así como la nueva traducción de La divina comedia se desprenden de la cartografía nacional y concilian la diferencia ubicándose en el seno del gran espacio intersticial del libro, es decir: el quilombo del Gran Chaco.

En conclusión, Roa Bastos ve en el nacionalismo una de las mayores fisuras del discurso de la integración. La construcción de un archivo conformado de memoria nacional y latinoamericanista exhibe problemas en su misma constitución. ¿Cómo integrar archivos contradictorios sin resolver sus problemas internos? Los conjurados propone emplazar el nacionalismo mediante una retroactuación sobre las memorias nacionales. Edgar Morin ha usado este término para referirse a la necesidad de tornar común el pasado mediante la convivencia reflexiva con los mismos conflictos (144). El estado-nación latinoamericano ha construido alteridades de "pueblos hermanos de culturas idénticas" (96). Los conjurados es una convocatoria para contemplar otra integración posible tomando como base el cuestionamiento de la identidad resultante de la cartografía nacional latinoamericana. La literatura recupera trayectorias alternativas de la desmemoria cultural que concomitantemente reflejan el lado oscuro del pasado regional y ofrecen perspectivas para superarlo.

\section{BiBLIOGRAFÍA}

Alighieri, Dante. La divina comedia. Bartolomé Mitre, trad. Buenos Aires: Editorial Sopena, 1938.

Altamirano, Carlos. "El orientalismo y la idea del despotismo en el Facundo". Ensayos argentinos. De Sarmiento a la vanguardia. Carlos Altamirano y Beatriz Sarlo, eds. Buenos Aires: Compañía Editora Espasa Calpe Argentina S.A., 1997. 83-102.

Benjamin, Walter. Illuminations. New York: Schocken Books, 1969.

Bhabha, Homi. The Location of Culture. New York: Routledge, 1994.

Brezzo, Liliana. "La historiografía paraguaya: del aislamiento a la superación de la mediterraneidad”. Revista Diálogos (2004): 109-121.

Burton, Richard F. Cartas desde los campos de batalla del Paraguay. Buenos Aires: Librería 'El Foro', 1998.

Chiavenato, Julio J. Genocidio Americano: A Guerra do Paraguai [1979] São Paulo: Editora Moderna, 1998.

Derrida, Jacques. “Des tours de Babel”. Psyché-Inventions de l'autre. Paris: Editions, 1998.

Donghi, Tulio Halperin. “Argentine Counterpoint: Rise of the Nation, Rise of the State”. Beyond Imagined Communities. Reading and Writing the Nation in NineteenthCentury Latin America. Sara Castro-Klarén y John Charles Chasteen, eds. Washington: Woodrow Wilson Center Press, 2003. 33-53. 
Gache, Belen. “Cándido López y la batalla de Curupaytí: relaciones entre narratividad, iconocidad y verdad histórica”. II Simposio Internacional de Narratología, Buenos Aires, 2001 (15 aug. 2004) http://belengache.findelmundo.com.ar/index.html>

Grimson, Alejandro. "Fronteras, migraciones y Mercosur. Crisis de las utopías integracionistas”. Apuntes de Investigación del CECYP 7 (2001): 23-64.

Loizaga, Patricio. Cándido López. Fragments and Details. A Photographic Search for New Semantics. New York: I.C.A.S.A., 1993.

Martínez, Tomás Eloy. “Roa todavía está aquí”. La Nación (28 abril 2005).

Mitchell, W. J. T. Picture Theory: Essays on Visual and Verbal Representation. Chicago/ London: University of Chicago Press, 1994.

Morin, Edgar. Penser l'Europe. Paris: Gallimard, 1987.

Pomer, León. La guerra del Paraguay, igran negocio! Buenos Aires: Ediciones Calden, 1968.

Rama, Ángel. La ciudad letrada. Hanover: Ediciones del Norte, 1984.

Ramos, Julio. Desencuentros de la modernidad en América Latina. México: Fondo de Cultura Económica, 1989.

Roa Bastos, Augusto y otros. Los conjurados del Quilombo del Gran Chaco. Buenos Aires: Alfaguara, 2001. y otros. O livro da Guerra Grande. Rio de Janeiro: Editora Recorde, 2002.

Said, Edward. Orientalism. New York: Vintage, 1979.

Sánchez Pórfido, Elisabet y otros. Cándido López, Florencio Molina Campos y Benito Quinquela Martín como paradigmas de la plástica argentina. Buenos Aires: Editorial de la Universidad Nacional de Mar del Plata, 1998.

Spariousu, Mihai. The Wreath of Wild Olive. Play, Liminality, and the Study of Literature. New York: State Unversity of New York Press, 1997.

Spivak, Gayatry . “Translator’s Preface”. Of Grammatology. Jacques Derrida, G. Spivak, trads. Baltimore: Johns Hopkin University Press, 1997.

Whigman, Thomas. "The Paraguayan War. A Catalyst for Nationalism in South America”. I Die with My Country. Perspectives on the Paraguayan War, 1864-1870. Hendrik Kraay y Thomas L. Whigham, eds. Lincoln: University of Nebraska Press, 2004. 179-199. 
